\title{
THE BENEFITS OF CUSTOMER RELATIONSHIP MANAGEMENT (CRM) IN THE HEALTHCARE INDUSTRY
}

\author{
Chester D. Thompson, Robert Morris University, cdtst10@rmu.edu
}

\begin{abstract}
The pharmaceutical industry has undergone rapid change due to the high cost of managing patient care. 'BIG Pharma' like other healthcare related industries have and continue to adapt to the changing business landscape via the use of innovative applications such as Customer Relationship Management (CRM), data mining, and personal healthcare portals to help gather relevant patient data. This paper examines current trends such as CRM, Data Mining, and Patient Health Care Portals (PHCP) as an example of how pharmaceutical organizations and health care related companies are utilizing emerging technologies toward migration to a patient-centric health care business model.
\end{abstract}

Keywords: Healthcare, Pharmaceutical, CRM, PHCP, Data Mining

\section{INTRODUCTION}

The pharmaceutical industry continues to evolve due to a number of factors such as rising healthcare costs, federal mandates like the HITECH Act, Obama Care, and PHARMA Code Regulations. As a result, pharmaceutical companies and other health care related organizations have and continue to modify their business model to better serve their constituents. Alt and Pushmann (2005) contended that information technology is at the core of this paradigm shift. Moreover, the authors and researchers stated that the emphasis will be on the development of Personal Health Care Information Portals and other technologies whereby the patient (customer) will be at the center of attention for pharmaceutical and healthcare related organizations.

\section{RESEARCH QUESTIONS}

This paper talks about the current strategies in the pharmaceutical industry that pertains to the following three questions:

R1: Due to the changing healthcare landscape, have pharmaceutical companies shifted from a sales representative business model to an on-line customer centric model?

R2: What are the implications of utility of Customer Relationship Management Applications (CRM) and data mining tools in the health care and pharmaceutical industry?

R3: Have Health Care Portals and CRM technology changed the way healthcare consumers engage doctors and access relevant medical data?

The Shift from Traditional Sales Tactics to an On-line Customer Interface Model

As a result of the changes occurring in the pharmaceutical industry, which ranges from internet sale of prescription drugs, educated consumers, and the continued pressure from government for 'Big Pharma' to reduce drug cost, the industry has started to look inward at how they have historically interacted with their customers and redefine their customer base. The pharmaceutical industry, unlike other industries, has begun to take small steps toward adopting CRM and other information technology to improve relationships with customers. Also, hospitals and other 


\section{Issues in Information Systems}

Volume 13, Issue 2, pp. 397-403, 2012

healthcare related organizations have initiated inter-organizational systems or (IOS) as a way of improving their relationships with key customers. Examples of these systems are McKesson, a major distributor of pharmaceuticals and Baxter, a leading hospital supplier. The overall goal of IOS is to improve the overall operating systems of these and many organizations to ensure an effective and efficient healthcare process (Alt and Pushmann, 2005).

The authors and researchers affirmed that due to the increased competitive environment and the emergence of selfhelp on line websites and portals, pharmaceutical companies are forced to reevaluate their existing sales strategies and develop strategies such as CRM applications and information technologies to better leverage their relationships with customers. However, the key component to a successful CRM implementation is to understand the customer and develop a process flow and system architecture that will meet the needs of the business and its customer base.

Moreover there are three strategic levels that must be (utilized/ incorporated) to move toward a successful business and system architecture development initiative: a strategy level that focuses on the customer in place of the product, the process level that emphasizes the development and reengineering of internal and external processes, and the system level that examines the system architecture of the firm such as middleware, web services, and process specific modules (Alt and Pushmann, 2005).

Michael Porter claimed that the internet has a powerful impact on industry structure and provides a long term competitive advantage. Further the author and researcher argued that due to its open system and technological advances, it levels the playing field and intensifies the competition while it substantially increases the available information to people; as a result it empowers the consumer (Porter, 2001).

Although, the migration from a traditional sales model to an on-line customer interface model appears to provide pharmaceutical companies with greater access to patients via CRM applications and other information gathering technologies, the quality of a healthcare provider's care and the potential for serious harm to consumers is unknown. The patient centric model certainly has its advantages for long term sustainability and customer relationships. However, patients can provide misleading or false information to gain access to medications (Bloom and Iannacone, 1999).

\section{The Benefits of CRM in the Pharmaceutical Industry}

For the purpose of this research study, the pharmaceutical industry is the focus of this discussion. Unlike other industries, it is the last industry to embrace CRM technology. In the pharmaceutical industry, most of the attention has been on doctors and other healthcare professionals that impact prescriptions and refills. Factors vary from physician and key stakeholders unwillingness to adopt technology and change to what has been historically a business to doctor business model. Further, the increased cost to find, develop, market, and promote new products is very costly and consequently pharmaceutical companies must embrace new initiatives so as to develop and profit from new innovative products.

Alt, Osterle, Pushmann, Barak, and Huber (2003) claimed that developing new products and improving the relationships with healthcare providers has and continues to be the principal way that pharmaceutical companies do business. Furthermore, the authors and researchers stated that other industries such as banking, retail, and technology fine tune their relationships with key customers; conversely the pharmaceutical industry, a major part of the healthcare industry is just at the beginning stage of learning about their customers (Alt et.al. 2003).

Foss, Stone and Ekinci (2008) stated that the pharmaceutical sector and other for profit industries such as banking, insurance and the telecommunications industry typically invest more aggressively in CRM strategies in an effort to 


\section{Issues in Information Systems}

Volume 13, Issue 2, pp. 397-403, 2012

minimize the cost of managing their customer base. Conversely, companies with tight profit margins invest more modestly in CRM projects or partner with other enterprises or structure a pay as you go arrangement.

Additionally several factors such as demanding healthcare consumers, limited access to healthcare providers, increased cost of pharmaceutical drugs and the government's continued effort to suppress cost by formulating more restrictive regulations are the main contributors to the pharmaceutical industry's migration toward a customer centric business model (Alt et.al.,2003).

The goal of Customer Relationship Management (CRM) is to know the customer better than anyone else, whether the customer is a person or business, with the end goal to maximize the business relationship with the customer. Oana Muntean stated that a company's most important asset is information. Information about a company's internal and external partners is vital to the success of the company. As such, the data warehouse is the foundational or starting point because it serves as a repository whereby all information that is gathered on customers is simply dumped, stored, or maintained where it can be later retrieved for future use.

To further explain, the author claimed that the data warehouse supports a complete view of the customers, including customer data, transactional, interaction, and behavioral data. As a result, customer data can be used to take advantage of future sales opportunities with customers (Muntean 2004). In the case of the pharmaceutical industry where patients utilize personal health care portals such as Web MD, transaction records show that individuals can obtain useful information on therapies, providers in their area, and support groups relevant to their inquiry.

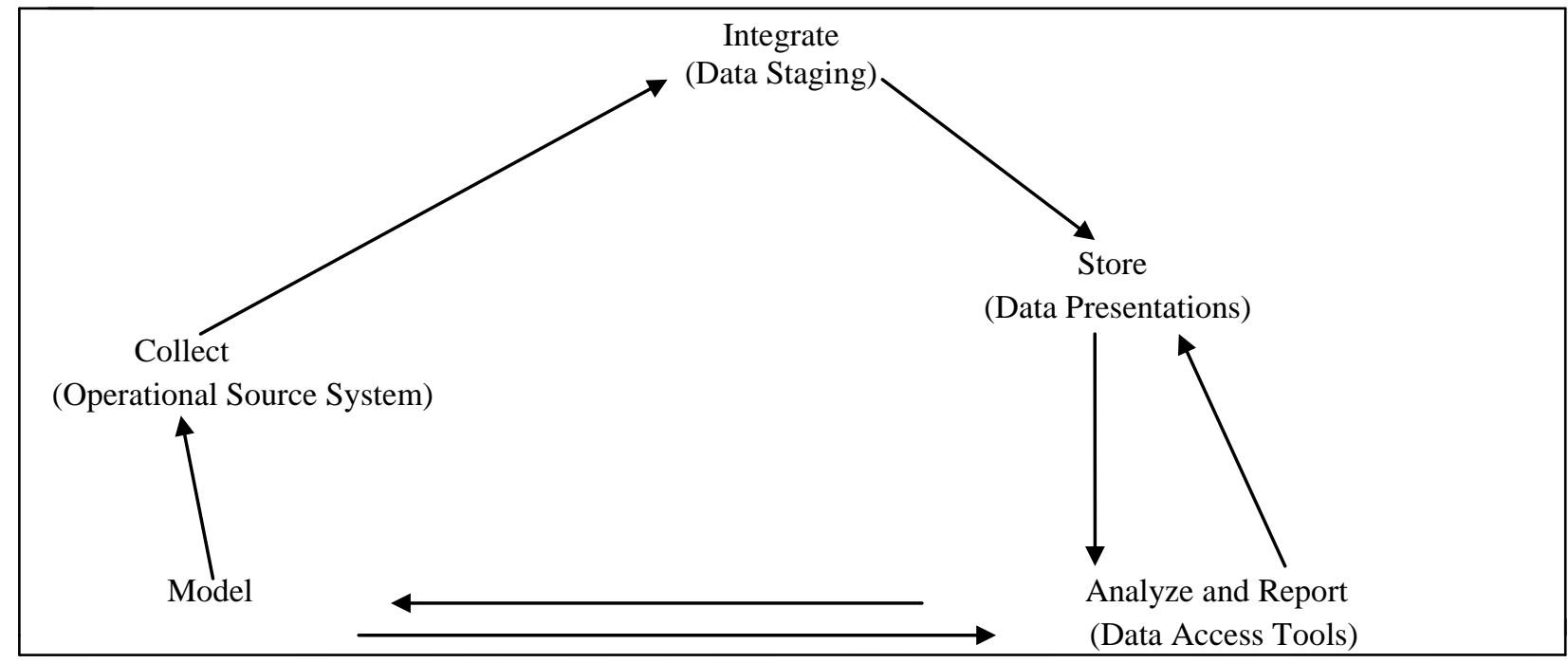

Figure 1. Analytic CRM

As depicted in the above conceptual drawing, as the company grows and becomes customer (patient) centric, the data warehouse (foundational) also will grow due to increased information about customers. Further the CRM application that interacts with the data warehouse is referred to as customer data repositories or (CDR) because of the need to provide lower level, granular customer transaction data (Muntean, 2004).

As the number of users with limited to no knowledge of specific search domains for health related information increases, the opportunity for more unsuccessful outcomes will increase. A key solution is to make available 


\section{Issues in Information Systems}

Volume 13, Issue 2, pp. 397-403, 2012

domain-specific search indicators as explicit as possible, as general purpose search engines do not provide these strategies. Bhavani claimed that end users will benefit from Strategy Portals that provide domain-specific knowledge to perform searches for information in unfamiliar domains (Bhavani, 2002).

Due to the increased pressures to contain (control) cost, competition from rival organizations and need to learn about and understand patients (customer) trends, Koh and Tan argued that data mining will be an essential resource for organizations determined to stay ahead of the game. Moreover, the authors and researchers claimed that data mining applications can benefit healthcare organizations such as large health systems, doctors and patients alike by identifying effective treatments and best practices. Additionally, due to the Balanced Budget Act of 1997, the Centers for Medicare and Medicaid Services were mandated to initiate a prospective payment system based on categorizing patients into a case-mix group. Examples of the utility and benefit of data mining tools was the development of a payment system for patients undergoing in-patient rehabilitation (Koh and Tan, 2011).

Further, Koh and Tan contended that due to the utility of data mining and CRM, healthcare organizations can better identify customers (patients) that may benefit from specific healthcare services, encourage patients who may require certain services to gain access to it, and continually improve the methods by which the healthcare organization(s) reach out to a specific target audience. As a result, data mining and CRM applications can lead to better treatment outcomes. For example, as revealed in Table 1, patients contained within an healthcare organization data set or repository that presents a health care provider with certain key variables such as: age, body mass index (BMI), the number of times a patient exercises weekly, onset of diabetes, a positive diabetes test result as measured by blood test can help with appropriate diagnostic and treatment protocols (Koh and Tan, 2011).

As part of the decision tree or algorithm that providers use, the data mining strategy (as based on the data warehouse) at a major healthcare organization is an effective way to determine how certain variables (as reviewed in both charts) are associated with the onset of diabetes and helps with interpretation of the data. The information contained in the data warehouse paired with utility of CRM can be used to help medical practitioners better predict how certain variables are associated with diabetes such as age, a smoker versus non-smoker and sedentary lifestyle. An older patient might be at a greater risk of diabetes, while a younger person would be at a more reduced risk. Furthermore, patients that present with a higher BMI reveal a greater affinity for diabetes (Koh and Tan, 2011).

Additionally, the pharmaceutical company will benefit from data mining and CRM by monitoring which healthcare provider prescribes certain pharmaceutical agents. The company is better armed and knowledgeable about specific physicians to target and help doctors decide on the best course of therapy and also specify certain practices that may be potential targets for clinical trials based on patient census and disease state awareness.

Lastly, the authors and researchers concluded that successful data mining and CRM initiatives require a continued commitment on the part of the healthcare organization. Further, it is a collaboration between all parties involved that leads to a successful and long lasting relationship. The data is only as good as the quality of input and access to the data. The future of data mining as it pertains to CRM is not limited to quantitative data such as physicians notes and clinical records but in the future imaging and other diagnostic data may be included as part of healthcare data mining and CRM technology initiatives. The emphasis of data mining and CRM technology is the positive contribution it makes to the patients, providers and the benefit to society at large (Koh and Tan, 2011). 


\section{Issues in Information Systems}

Volume 13, Issue 2, pp. 397-403, 2012

lavie 1. Sigimicant variavies

\begin{tabular}{|c|c|c|c|}
\hline \multicolumn{2}{|c|}{ Level $^{*} /$ Variables } & \multicolumn{2}{|c|}{ Chi-square Statistic (p-value) } \\
\hline 1 & / Age & 463.84 & $(<0.0001)$ \\
\hline \multirow[t]{2}{*}{2} & / Body mass index & 184.99 & $(<0.0001)$ \\
\hline & Body mass index & 98.66 & $(<0.0001)$ \\
\hline \multirow[t]{3}{*}{3} & / Age & 26.72 & $(<0.0001)$ \\
\hline & Waist hip ratio & 32.33 & $(<0.0001)$ \\
\hline & Waist hip ratio & 40.34 & $(<0.0001)$ \\
\hline \multirow[t]{3}{*}{4} & / Body mass index & 17.63 & $(<0.0001)$ \\
\hline & Number of times of exercise per week & 10.19 & $(0.0014)$ \\
\hline & Age & 10.49 & $(0.0013)$ \\
\hline
\end{tabular}

* Level refers to the depth of the decision tree as shown in Figure 1 Decision Tree.

Figure 2. Significant Variables

Figure 2 reveals key variables that physicians use as part of their diagnostic routine to determine a patients diagnosis of diabetes.

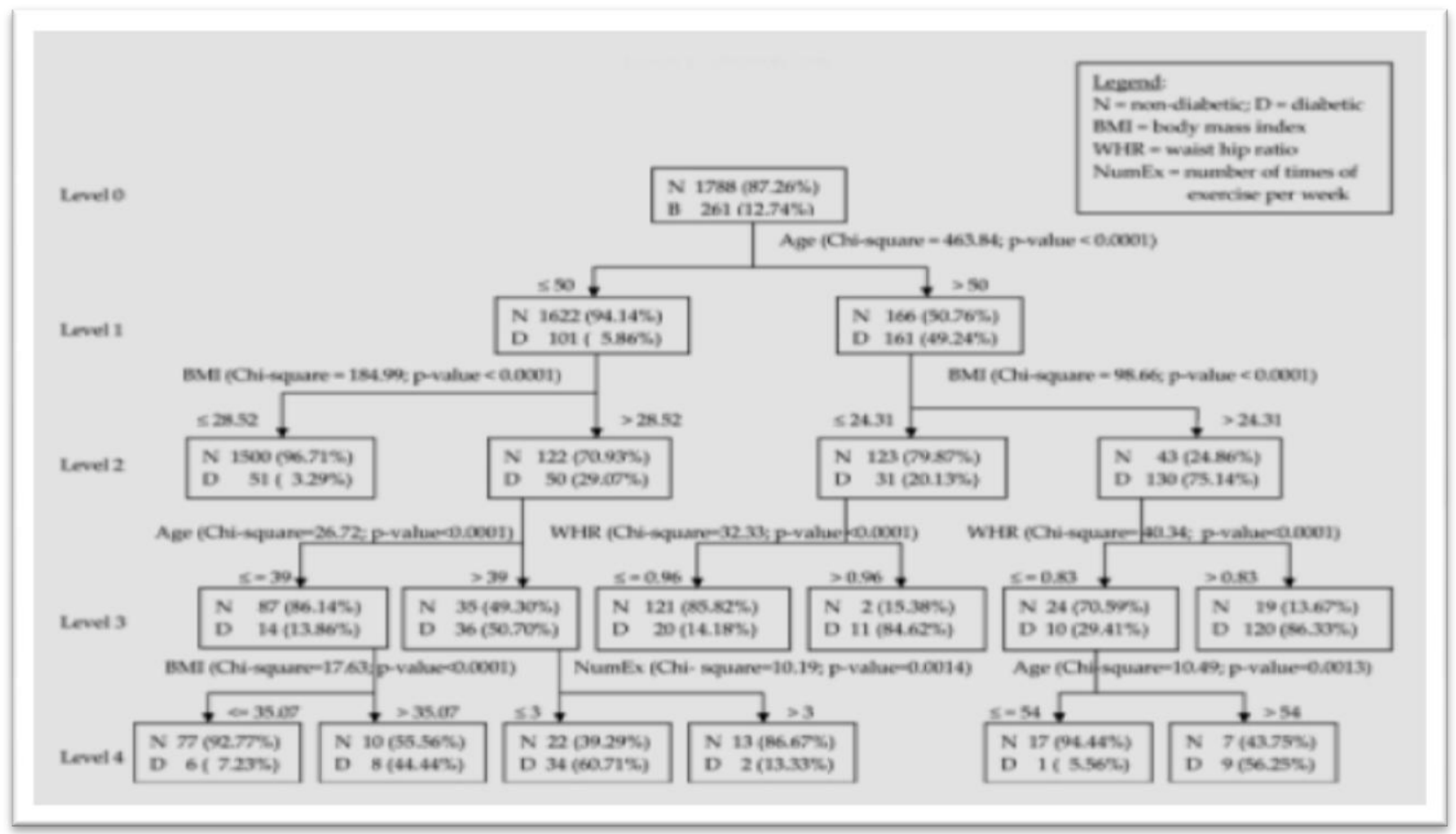

Figure 3. Decision Tree

Mary Obenshain asserted that data mining is located at the confluence of statistics, database technology, pattern recognition, machine learning data visualization and expert systems (Obenshain, 2001). As demonstrated in figure 3 , 


\section{Issues in Information Systems}

Volume 13, Issue 2, pp. 397-403, 2012

it encompasses a variety of analytical techniques and methods as utilized in a number of healthcare and pharmaceutical organizations to better understand and learn from a large and diverse quantity of data.

\section{HealthCare Portals and CRM Technology}

As a result of rising healthcare cost, increased competition, and restrictive government rules and regulations, the pharmaceutical industry faces a dilemma; continue business as usual or face diminishing revenue and growth. Health care portals or intermediaries as they are referred to in the marketplace have gained popular appeal because of their ability to bring an added value to customers and suppliers. Further, as these portals are able to interface with Customer Relationship Management (CRM) tools they allow pharmaceutical companies and healthcare organizations to achieve increased customer centricity (Pushmann, Thalmann, and Alt, 2001). Prior to the advent of healthcare portals, organizations focused on the products and services they offered with little or no attention to their customers as depicted in figure 4 .
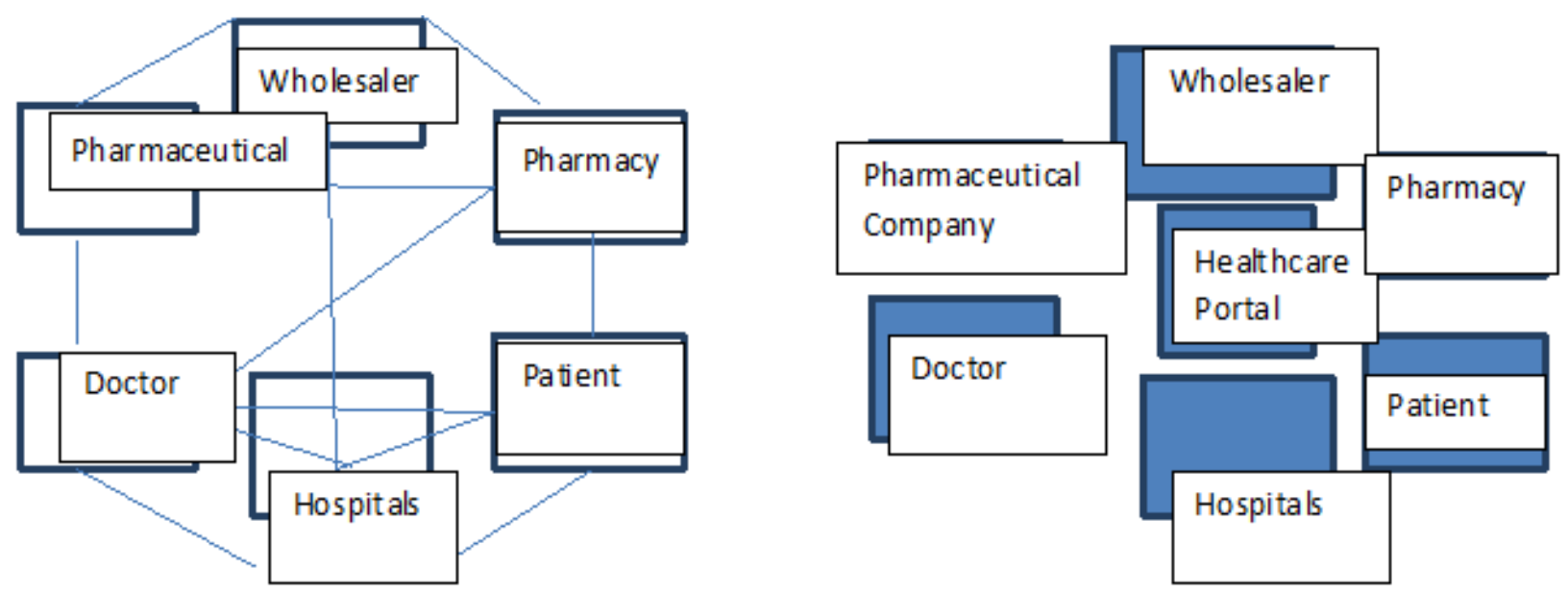

Figure 4. Pharmaceutical and Healthcare Paradigm Shift

Hence, the emergence of healthcare portals has changed the pharmaceutical industry business process, placing the customer at the center of attention. Consequently, the interface of the two technologies will help drug manufacturers increase their bottom line while fostering and improving relationships with their customers. Although, customer centricity is the core objective for data mining, healthcare portals and CRM initiatives, the pharmaceutical industry continues to place their products and services at the core of their business practice and is beginning to utilize CRM and other technology strategies to increase market share. Healthcare consumers unlike other customers are always in the process of being prescribed a medication and subsequently cured of their disease state or condition. Therefore pharmaceutical and healthcare industries will require a diverse portfolio of products and resources that they collect from a number of suppliers. Vendors that put together all the prerequisite services for a particular customer process by way of healthcare portals will bring forth a tremendous added value in the healthcare sector (Pushmann, Thalmann, and Alt, 2001). 


\section{Issues in Information Systems}

Volume 13, Issue 2, pp. 397-403, 2012

\section{CONCLUSIONS}

This paper sought to explain the emergence of CRM applications and other technology innovations impact on the pharmaceutical sector. CRM strategies and other information gathering tools such as data mining and use of web based healthcare portals have and continue to alter the pharmaceutical industry by focusing on the customer rather than only on the products and services they provide. Furthermore, a pharmaceutical company can no longer rely solely on its' large armies of field sales professionals to deliver the message about their products and services offered. This outdated strategy will almost inevitably produce a less than desirable outcome in sales and overall profit margins.

Further, as drug production and other related costs continue to rise and are met by increased competition from cheaper generic alternatives, it will be imperative that drug makers and other key players in the drug industry evaluate and align their business process towards a more customer centric approach by utilizing advanced technologies such as CRM, data mining tools and healthcare portals. The benefits of such measures will far outweigh the upfront investment cost of implementing a CRM business strategy because as issues such as limited access to healthcare providers, increased government intervention and the continued rise of healthcare becomes more prevalent, the use and benefit of CRM will be substantial.

Finally, the research does show that the use of CRM strategies, data mining and personal healthcare portals have changed how healthcare consumers engage healthcare providers because patients are able to access personal healthcare records, learn about their diagnosis and treatment options and be better informed about their overall health and wellness by the simple click of a button and access to the internet. This is significant because the research reveals that technology will continue to play a significant role in the future of the pharmaceutical industry due to the complexity and competiveness of the business environment.

\section{REFERENCES}

1. Alt, R., \& Puschmann, T. (2005). Developing Customer Process Orientation-The Case of Pharma Corp. Business Process Management Journal, 11 (4), 297-315.

2. Bhavani, S. (2002). Domain-Specific Search Strategies for the Effective Retrieval of Healthcare and Shopping Information. CHI, 610-611.

3. Bloom, B. (1999). Internet Availability of Prescription Pharmaceuticals to the Public. Annals of Internal Medicine 11 (131), 830-831.

4. Foss, B., Stone, M. \& Ekinci, Y. (2008).What Makes for CRM System Success-or Failure? Database Marketing and Customer Strategy Management 15 (2), 68-78.

5. Huber, T., R. Alt, \&V. Barak (2000). Future Application Architecture for the Pharmaceutical Industry. From the Selected Works of Hubert Oesterle.

6. Koh, H., \& Tan, G. (2011). Data Mining Applications in Healthcare. Journal of Healthcare Information Management 19 (2), 64-71.

7. Muntean, M. (2004). Data Warehouse Solutions for CRM.International Conference on Computer Systems and Technologies-CompSysTech, 11-6-1-11-6-4.

8. Obenshain, M. (2004). Application of Data Mining Techniques to Healthcare Data. Infection Control and Hospital Epidemiology, 25 (8)690-695.

9. Porter, M. (2001). Strategy and the Internet.Harvard Business Review, 2-20.

10. Puschmann, T., O. Thalmann \& Alt, R. (2001). Healthcare Portals-Customer Centricity In The Pharmaceutical Industry. Global Co-Operation in the New Millennium, 410-421. 